What surprised us at the time was that, despite the obvious relationship to a cross wind, the prevailing breeze was almost imperceptible.

\section{Barron Crutckshank.}

B. Falkner Lewis.

Papworth Hall, Cambridgeshire.

Nature, 155, 243 (1945).

2 cf. Bauchmetz and Whitehouse, Nature, 155, 243 (1945); "frequency approximately 10 a second".

\section{Effect of Substituents on the Oxidation Potential of Ferrous ortho-Phenanthroline Complexes}

IN a recent communication ${ }^{1}$, Smith and Richter have measured the oxidation-reduction potentials of a series of substituted ortho-phenanthroline iron complexes.

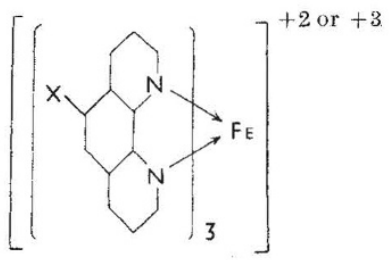

The values obtained show a marked trend with the dipole moments of the corresponding substituted benzenes. More striking, however, is the fact that a linear graph is obtained when these formal oxidation-reduction potentials are plotted against the (negative) logarithms of the dissociation constants ${ }^{2}$ of the corresponding para-substituted benzoic acids.

$E_{0}$ and $\log K_{a}$ are, of course, proportional to the free energy changes of the corresponding reactions. Clearly, an electron shift, for example one towards the substituent group, which in the acid series raises

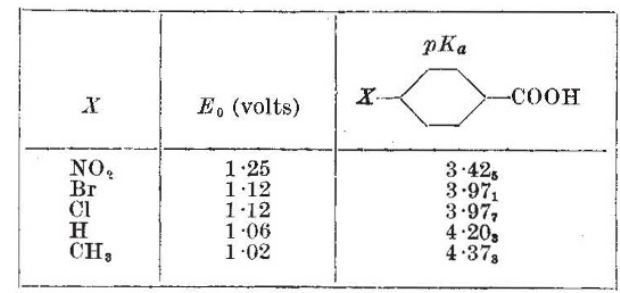

The equation to the line is $E_{0}=2 \cdot 08_{2}-0 \cdot 243\left(p K_{a}\right)$.

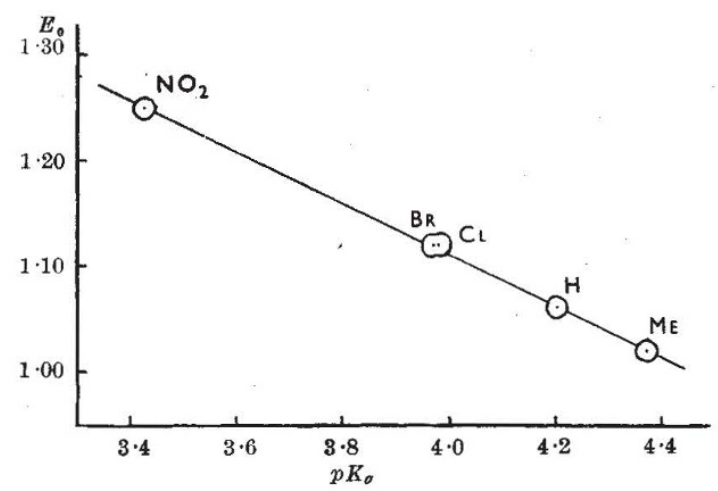

the acid strength by increasing the repulsion on the proton, is similarly transmitted in the complex ion. The withdrawal of electrons is communicated through the co-ordinated nitrogen atoms to the central iron atom, to produce an increased binding of its electrons and a proportionate rise in the oxidation potential.

R. V. G. Ewens.

\section{Chemistry Department,}

Guy's Hospital Medical School, London, S.E.I.

${ }^{1}$ Smith and Richter, Ind. Eng. Chem. (Anal. Ed.), 16, 580 (1944).

Dippy et al., J. Chem. Soc., 1888 (1934); 343 (1935); 644 (1936).

\section{Causality or Indeterminism ?}

I HOPE it will not cause Nature to lose caste for a very ordinary man to join in the discussion on causality v. indeterminism so ably dealt with by Prof. H. T. H. Piaggio, and to express thoughts that will at least be understood by all who try to read the exceedingly specialized correspondence columns.

I follow the line of argument that coin tossing is not really haphazard but governed by strict laws of causality, although the variation in launching and wind may be impossible scientifically to calculate. Incidentally, the alternative of red and black on a roulette board is the incalculable ideal, in that the ball launched round the board in the opposite direction to the spinning centre has to strike odd-shaped obstacles before rolling into the middle. Results have, I understand, for some obscure reason been chronicled for years.

When we come to atomic physics we get into heavy weather and we are not really helped by von Neumann's six laws, especially the one referring to the 'squared operator' which may convey that there is something wrong with the 'tote', but is otherwise entirely incomprehensible to the layman. Anyhow, at present the pundits plump for indeterminism.

How can this refreshing individuality in atomic physics, so stimulating in our dragooned world, react on 'homo sapiens' (sic) ?

In Schrödinger's attractive book "What is Life?" with Darlington prompting him 'off', as they say on the stage, he tells us that we mortals are made a certain size in order that statistical results should obtain. A serious corollary, however, emerges in that genes are so small as to be subject to random changes as, for example, in the energy-level of their few constituent atoms. These changes are enough to account for mutants. Through no fault of our own, therefore, we may become the parents of monsters. May we now go further and be told by those who analyse the micromechanism that animates the brain whether there are there, constituent parts of such small size as also to be influenced by random atomic changes. If such be so, then the truly awful thought faces us, that all our wise decisions, all our noble or possibly questionable actions in life, are determined, not by our own highcharactered and noble 'ego', but by a microscopic atomic material part of our brain, over which we have no control, being bumped around on the quantum level.

These are grave thoughts, but if the latter hypothesis be true, although not exactly comforting, it would at least explain and indeed excuse many mistakes made in life by your obedient servant,

Brabazon of TARa. 